\title{
A BUSCA POR VANTAGEM COMPETITIVA NO SEGMENTO MARKETPLACE
}

Eros Augusto Asturiano Martins ${ }^{1}$

Moises Ari Zilber ${ }^{2}$

${ }^{1}$ Programa de Pós-Graduação em Administração de Empresas / Centro de Ciências Sociais e Aplicadas (CCSA) / Universidade Presbiteriana Mackenzie

${ }^{2}$ Programa de Pós-Graduação em Administração de Empresas / Centro de Ciências Sociais Aplicadas (CCSA) / Universidade Presbiteriana Mackenzie 


\section{A BUSCA POR VANTAGEM COMPETITIVA NO SEGMENTO MARKETPLACE}

Resumo: Entender como as empresas de marketplace obtém vantagem competitiva foi o objetivo principal deste artigo. Mas, buscou-se também uma definição sobre marketplace, um novo segmento de negócio que ainda não possui muitos estudos publicados. A pesquisa foi feita com sete empresas e os resultados apresentados demonstram que a diferenciação é fonte de vantagem competitiva e que ela ocorre por meio da inovação. Outra contribuição deste trabalho foi identificar que a inovação faz parte da cultura dos marketplaces e que existe uma ligação entre inovação e vantagem competitiva no segmento pesquisado.

Palavras-chave: Vantagem Competitiva. Inovação. Diferenciação. Marketplace. 


\section{Introdução}

A administração estratégica busca traçar os caminhos que serão trilhados pela empresa com o objetivo de alcançar retornos acima do investimento. Para isto, é fundamental que seja gerada uma vantagem competitiva, que segundo Coyne (1986) e Porter (1989) acontece quando a empresa consegue executar atividades estrategicamente importantes de uma forma mais barata ou melhor do que a concorrência, garantindo um desempenho superior aos seus concorrentes. Neste sentido, as empresas necessitam buscar novos caminhos para obterem esta vantagem, que segundo Porter (1989), é uma criação de valor que pode ocorrer pela diferenciação ou liderança em custos. Em complemento, Consoni et al (2010) definem que as empresas podem alcançar vantagem competitiva por meio da inovação, que é definida por Tidd e Bessant (2015) como sendo uma exploração bem-sucedida de novas ideias.

Ampliando um pouco mais o escopo da inovação, Montgomery (1998) afirma que a inovação pode ser manifestada de diversas maneiras, por exemplo, um novo produto, um novo processo, uma nova abordagem de marketing, um novo modo de comercialização.

A relação entre vantagem competitiva e inovação também é observada por Barney e Hesterly (2008) quando os autores explicitam que inovar em aspectos pouco explorados pelos concorrentes contribuem para que as organizações desenvolvam uma vantagem competitiva.

Assim, o estudo da inovação como ferramenta para a busca por vantagem competitiva que proporcione à empresa um diferencial é de extrema relevância, conforme citam Tidd e Bessant (2015), as empresas necessitam criar novos bens e serviços ou alterar o modo de ofertar seus produtos para que não corram o risco de ser superadas por outras que o façam.

Para as micro e pequenas empresas isto também é importante, conforme Shane (2003) cita que empreendedores necessitam buscar identificar oportunidades para lançar produtos ou serviços inovadores que os diferenciem no mercado, para que tenham mais chances de concorrer com os rivais já estabelecidos e o fazem por meio de um processo visionário, no combinando recursos e habilidades de negócios.

No mesmo sentido, Bruyat e Julien (2000) escrevem que a inovação para empreendedores acontece quando existe a criação de valor, a qual é transformada na oferta de produtos inovadores, os quais contribuem para o crescimento da empresa.

Vianna et al (2016) escrevem que o cenário atual da inovação no Brasil existe um grande potencial que ainda é pouco explorado pelas empresas e governos, mas ressalta projetos em andamento cujo foco é alavancar a vantagem competitiva por meio de novos produtos/serviços e da otimização dos processos de venda. Esta última característica é o foco deste artigo, que buscará verificar como ocorre a criação de vantagem no setor de marketplace, o qual surgiu em 1996 com o eBay - o qual era uma pequena empresa de leilões online - e que criou sua vantagem competitiva ao inovar o processo de venda pela internet, possibilitando que pessoas físicas pudessem vender pelo site, além de incluir as avaliações dos compradores e vendedores.

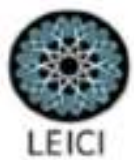


Atualmente, marketplace é um modelo de negócio online baseado na intermediação entre compradores e vendedores que possibilitam a comercialização por meio de sua plataforma (CAMPOS et al, 2015). Estes novos modos de comércio estão ganhando mercado pois reúnem pequenos produtores e consumidores em um mesmo ecossistema (ALSTYNE, PARKER E CHOUDARY, 2016).

A relevância deste segmento no Brasil pode ser comprovada com dados do Relatório Webshoppers (2017) do e-bit, o qual revela a crescente contribuição do marketplace para o ecommerce, que faturou $\mathrm{R} \$ 44,4$ bilhões em 2016, registrando um crescimento nominal de 7,4\% em relação ao ano anterior. Deste montante, cerca de $30 \%$ corresponde ao marketplace, ultrapassando R \$ 13 bilhões. Segundo dados do relatório da agência We Are Social (2015), 54\% da população brasileira são usuários ativos de internet e 36\% já compraram algo online.

O Relatório Webshoppers (2017) também ressalta que mesmo com algumas empresas do ecommerce já estarem vendendo por meio de marketplaces, outras ainda não perceberam o impacto das mudanças que este setor está promovendo no mercado. Com isto, podemos perceber que o marketplace pode contribuir muito com o faturamento do comércio eletrônico, pois existe um grande potencial de crescimento por ser um modelo de negócio mais recente. Em consonância com o apresentado até aqui, Bogers, Afuah e Bastian (2010) escrevem que o ritmo acelerado das mudanças tecnológicas e a crescente sofisticação dos usuários significam que cada vez mais consumidores terão mais oportunidades de inovar ou contribuir para inovações nos produtos. Isso constitui uma grande oportunidade para os pesquisadores aprofundarem os estudos nesta área.

Como forma de buscar ampliar os estudos acerca da relação entre inovação e vantagem competitiva aplicada aos marketplaces, o problema de pesquisa proposto é: Como é criada uma vantagem competitiva no setor de marketplace?

\subsection{Objetivo Geral}

Identificar como ocorre a criação de vantagem competitiva, por meio de uma pesquisa qualitativa do setor marketplace.

\subsection{Objetivos Específicos}

- Verificar a ocorrência de criação de vantagem competitiva no setor marketplace;

- Analisar se a inovação pode contribuir na criação de vantagem competitiva.

\section{Referencial Teórico}

\subsection{Vantagem Competitiva}

O conceito de vantagem competitiva é abordado por Ansoff (1965) quando o autor se refere como sendo uma lucrativa posição concorrencial alcançada pela adequação de produtos a mercados. Este conceito foi complementado por Porter (1989) e, posteriormente, McGrath (2014) como sendo algo superior que uma empresa detém perante seus concorrentes e que ocorrem em níveis de performance econômica acima da média de mercado em função das estratégias. Por outro lado, Amit e Shoemaker (1993) incluem a posição do empreendedor como

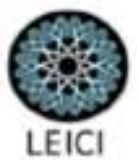


fundamental para que o retorno financeiro superior, pois o desafio da gestão é identificar, desenvolver, proteger e alocar os recursos de maneira que forneçam à empresa uma vantagem competitiva.

Mesmo com diferentes enfoques é possível verificar que para a criação de uma vantagem competitiva é importante que uma área da organização seja diferenciada. (PORTER, 1989; CONSONI et al, 2010). Neste sentido, Prahalad e Hamel (1990) propuseram que para se diferenciarem as organizações necessitam descobrir suas competências essenciais (Core Competences). Quanto mais bem desenvolvidas estas, maior vantagem competitiva sobre seus concorrentes elas terão.

Barney e Hesterly (2008) vão além e propõem que as empresas não podem esperar obter vantagens competitivas quando os recursos são uniformemente distribuídos entre todos seus concorrentes. Isto reforça a importância da diferenciação com fonte para a criação da vantagem competitiva. Barney (1991) desenvolveu um modelo para analisar se existe potencial para os recursos da organização se tornarem vantagem competitiva. Segundo o autor, o recurso deve possuir quatro atributos: a) ser Valioso: explorando as oportunidades e neutralizar ameaças no ambiente; b) ser Raro: entre a concorrência atuais e potenciais; c) ser Inimitável: ou seja, difícil das outras empresas imitar; d) ser Organizado: a ponto da empresa ser capaz de explorar este recurso. Este modelo é denominado de VRIO, pelas iniciais de Valioso, Raro, Inimitável e Organizado. Por meio deste método é possível verificar se um recurso é uma vantagem competitiva sustentável na empresa e Winter (1998) cita que uma vantagem competitiva sustentável pode ter como base alguns tipos de inovações em processos, pois estes são menos sujeitos à imitação pelos concorrentes.

Neste sentido, Silva e Dacorso (2013) analisam que o foco da vantagem competitiva ocorre nos processos de mudança, inovação e dinâmica da concorrência e tem como base a descoberta interativa de novas informações e conhecimentos, para que as oportunidades sejam identificadas. Isto posto, torna-se relevante o estudo da inovação como fonte de vantagem competitiva.

\subsection{Inovação}

Schumpeter (1939) é dos precursores do estudo da inovação, o qual a definiu como sendo a criação de um novo produto ou uma nova função a ele por meio de um processo dinâmico no qual novas tecnologias substituem as antigas, resultando na destruição criativa. Este conceito também foi descrito no Manual de Oslo (2005, p. 46) como sendo "a implementação de um produto/serviço novo ou significativamente melhorado, ou um processo, ou um novo método de marketing, ou um novo método organizacional nas práticas de negócios, na organização do local de trabalho ou nas relações externas".

Tidd e Bessant (2015) classificam os diferentes tipos existentes na inovação, os quais são denominados como inovação: 1) de produto/serviço: mudanças no que uma empresa oferece; 2) de processo: mudanças na forma como os produtos/serviços são criados e entregues; 3) de marketing / de posição: mudanças no contexto em que produtos/serviços são introduzidos; 4) organizacional / de paradigma: Mudanças nos modelos mentais subjacentes que orientam o que a empresa faz.

É possível observar que o conceito de inovação é amplo e Tidd e Bessant (2015) complementam que, além dos tipos, existem também diferentes níveis de inovação, que vão
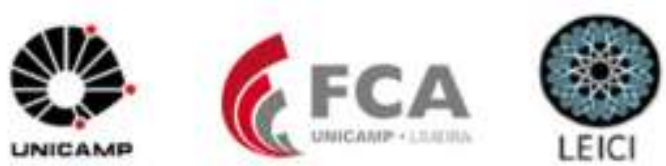
desde melhorias menores (inovação incremental) até grandes mudanças (inovação radical), que realmente transformam a forma como as percebemos e utilizamos os produtos/serviços.

Para melhor vislumbrar as diferenças entre estes níveis, Tironi e Cruz (2008) definem inovação radical como sendo aquela que se baseia em uma novidade tecnológica ou mercadológica e leva à criação de um novo mercado ou segmento, podendo (ou não) acarretar a descontinuidade do mercado existente. Já a inovação incremental apenas incorpora melhorias nas características técnicas, utilizações e/ou custos a produtos e processos já existentes.

A capacidade de a inovação gerar novos ou melhores produtos ou serviços também é citada por Zilber, Perez e Lex (2009) quando conceituam inovação como sendo uma habilidade de criar novos produtos que incorporem tecnologias diferentes das existentes e que satisfaçam as atuais necessidades dos consumidores e isto vai ao encontro com que escreve Drucker (2001) quando o autor cita que a inovação é o principal meio de uma empresa produzir recursos e criar novas riquezas.

Nesse mesmo sentido, Szeto (2000) e Forsman (2011) classificam a capacidade de inovação como uma melhoria contínua dos recursos e capacidades que possibilitam às empresas desenvolver novos produtos e explorar novos mercados. Mas inovar não trata apenas de criar novos mercados, mas também, oferecer novas maneiras de servir a mercados já maduros e estabelecidos (TIDD e BESSANT, 2015).

Shane (2003) escreve que as empresas estabelecidas têm mais potencial na exploração de uma oportunidade do que novas empresas, por cinco motivos: curva de aprendizagem, reputação, fluxo de caixa, economias de escala e recursos complementares. Entretanto, Christensen (2001) acredita que as empresas menores têm mais chance de desenvolver uma inovação disruptiva, que segundo o autor são aquelas que afetam o ciclo de vida dos produtos e suas dinâmicas competitivas. Estes produtos tendem a ser mais simples, mais baratos e mais confiáveis e convenientes dos existentes no mercado.

Explicitando a relação entre inovação e vantagem competitiva, Montgomery (1998) cita que algumas inovações criam vantagem competitiva por perceberem uma oportunidade de mercado inteiramente nova ou atenderem a um segmento de mercado que os demais ignoraram.

É possível as empresas obterem vantagem competitiva por meio de ações inovadoras. Estas ações atingem a inovação em seu sentido mais amplo, incluindo tanto novas tecnologias quanto novas maneiras de fazer as coisas (PORTER, 1989). Isto corrobora com as definições de inovação de Tidd e Bessant (2015) que também complementam explicando que independente das condições tecnológicas, sociais ou mercadológicas envolvidas, a fonte para criar e manter uma vantagem competitiva tende a pertencer àquelas organizações que continuamente inovam.

Em outro aspecto que a inovação contribui para a organização é atuando no modelo de negócio, o qual Chesbrough (2012) escreve que é tão importante quanto a inovação na tecnologia, pois uma mesma tecnologia comercializada de duas maneiras distintas irá produzir dois resultados distintos. Isto significa que muitas empresas podem se destacar inovando no modo que comercializam seus produtos/serviços e isto pode ser considerado como inovação.

Zilber et al (2008) atentam para que embora a inovação esteja geralmente ligada à avanços tecnológicos nos produtos ou processos, a maioria das inovações de sucesso está pautada no acúmulo de mudanças incrementais dos produtos ou processos. É importante

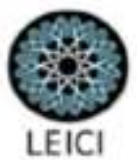


destacar que para que uma inovação seja fonte de vantagem competitiva, não necessariamente, esta precisa ser radical.

Neste sentido, Roper e Arvanitiz (2012) escrevem que a inovação não se limita à criação de produtos, pois ela também pode estar pautada em tornar os processos dinâmicos para receber e lidar com inovações rentáveis, por meio de práticas e atividades flexíveis. E isto somente é possível com o mapeamento de fatores organizacionais que são listados por Tidd et al (2005) como liderança e desejo de inovar; estrutura organizacional apropriada; clima organizacional criativo.

Conectando estes conceitos com o setor foco deste estudo, Bogers, Afuah e Bastian (2010) escrevem sobre a inovação nos setores de bens de consumo e identificaram que uma parte significativa da inovação e do desenvolvimento de produtos pode ser atribuída aos consumidores. Este ponto também é abordado por Robertson (1999) quando cita que o processo da evolução tecnológica advém da evolução das necessidades dos clientes e, também, da intensidade da competição do segmento. Assim, o segmento escolhido para este artigo configura como sendo de grande relevância para o estudo da inovação, tendo em vista o ajuste promovido pelos consumidores no modo de comercialização que o marketplace proporciona aos vendedores e compradores.

\section{Setor: Marketplace}

Dentre os tipos de inovação descritos no Manual de Oslo (2005) e por Tidd e Bessant (2015) encontra-se como exemplo da inovação de marketing (ou de posição), a introdução de um novo canal de distribuição com objetivo de atingir um novo público-alvo. Neste sentido, o segmento de marketplace é setor foco deste estudo por se tratar de um modelo de negócio novo no qual o grande diferencial trabalhado pelas empresas deste segmento atuarem como intermediadores de negócios.

O termo marketplace surgiu em meados dos anos 1996 nos EUA como um modelo de negócios do eBay, que iniciou como um pequeno site de leilões online, mas se tornou uma potência quando se tornou uma plataforma de compra e venda de produtos, no qual os sellers (vendedores) são pessoas físicas, o que fez expandir rapidamente seu portfólio de produtos. $\mathrm{O}$ conceito de marketplace é baseado na venda de produtos de vários fornecedores em um único ambiente, funcionando como um intermediador na venda online, mediando as relações de troca entre o vendedor e o comprador (Campos et al, 2015).

Alstyne, Parker e Choudary (2016) citam que o ecossistema destas plataformas de negócios tem a mesma estrutura básica, dos quais existem quatro protagonistas: os proprietários: controlam a propriedade do conteúdo e fazem a governança; os fornecedores: que servem como a interface entre a plataforma e o usuário; os produtores: que comercializam os produtos; os consumidores: que adquirem os produtos.

Segundo o Serviço Brasileiro de Apoio às Micro e Pequenas Empresas (SEBRAE, 2014), na maioria das vezes os marketplaces atuam como uma loja virtual onde se vende produtos e serviços. Surgiu como um modelo de negócio e se tornou conhecido por conectar diretamente cliente e fornecedor sem participação de intermediários. Sua monetização acontece a partir de um percentual na transação realizada. Para Wigand (1997), a desintermediação é o deslocamento de intermediários de mercado (distribuidores, varejistas), permitindo com que o
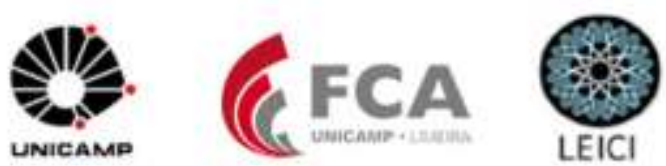
comércio entre compradores e consumidores aconteça diretamente, contribuindo assim para que novos empreendedores surjam no mercado.

Em geral, reúne diferentes tipos de produtos e serviços a fim de atingir o maior número de clientes possíveis, mas hoje existem também marketplaces especializados em um segmento de negócio como, por exemplo, roupas, livros, artesanatos (SEBRAE, 2014).

Ainda de acordo com o Sebrae (2014), este tipo de comércio eletrônico tem gerado oportunidades para pequenos negócios, por conta da variedade de produtos e serviços. Ao fechar parcerias com marketplaces, pequenas empresas podem comercializar sua produção nesses sites. Por outro lado, para os marketplaces estas parcerias têm como benefícios o aumento no volume no tráfego e não precisam manter estoque dos produtos, nem dominarem o know-how dos serviços oferecidos.

Alguns autores denominam os marketplaces como "agregadores de ofertas de produtos" como Soares (2013) escreve que para os vendedores, os benefícios são o grande número de acessos e de usuários cadastrados no site, o que traz uma maior capilaridade para a marca, tráfego de qualidade, além de um sistema de pagamento e logística integrados oferecidos por algumas plataformas e tudo isto por um baixo custo de investimento. Já para os compradores, uma gama de produtos diferenciados e preços atrativos são os principais chamarizes para este segmento.

A relevância deste segmento para este estudo é evidenciada com base em dados divulgados por Carneti (2015) e Campos et al (2015) em referência ao maior representante deste setor na América Latina, o Mercado Livre - o qual atua desde 1999, presente em 13 países e que alcançou, somente no Brasil, 556,5 milhões de dólares em sua receita líquida em 2014, obtendo um crescimento anual de $17,8 \%$. No ano em questão, foram comercializados mais de 101 milhões de itens, um aumento de $22 \%$ em relação a 2013. Campos et al (2015) também citam que a partir de fevereiro de 2014, grandes varejistas como Walmart, Extra.com, Submarino e Livrarias Saraiva iniciaram seus projetos de ampliar suas lojas virtuais para o modelo de marketplace, e hoje também já atuam neste segmento.

\section{Procedimento Metodológico}

Com base nos objetivos deste artigo, foi desenvolvida uma pesquisa exploratória qualitativa em empresas do segmento marketplace. Este tipo de estudo, segundo Wolcott (1994) apud Creswell (2010), é fundamentalmente interpretativa, pois o pesquisador faz uma interpretação dos dados, incluindo a descrição de uma pessoa ou de um cenário, análise de dados para identificar temas ou categorias e, finalmente, tirar conclusões sobre seu significado.

Barros e Lehfeld (2003) também contribuem neste tema quando escrevem que a pesquisa científica é a exploração por meio de um procedimento sistemático e intensivo que têm por objetivo descobrir e/ou compreender os fatos que compõem uma determinada realidade. No mesmo sentido, Bardin (2010) escreve que a análise de conteúdo busca conhecer aquilo que está por trás das palavras que são ditas, o que contribui para um entendimento mais aprofundado do tema estudado.

A população determinada para as entrevistas, foi composta por empresas do segmento marketplace. Dentre os respondentes, todos encontram-se em cargos de gestão, sendo sócios, CEOs (Chief Executive Officer) ou gestores. Para este trabalho, a técnica adotada foi de uma amostra não-probabilística por conveniência, que segundo Mattar et al (2014) é aquela na qual

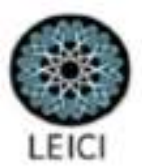


a seleção dos elementos da população depende, ao menos em parte, do julgamento do entrevistador no campo. Levine et al (2008) complementa que a amostragem não-probabilística ocorre quando a probabilidade de os elementos da população pertencer à amostra é desconhecida. Neste estudo, a amostra por conveniência foi composta de sete entrevistas em empresas que atuam no setor de marketplace, sendo varejo (produtos variados), eletrodomésticos, artesanato, roupas e acessórios, alimentação e prestação de serviços.

\section{Resultados e Análises}

Neste capítulo os resultados das entrevistas serão transmitidos, objetivando a demonstração de pontos relevante a este trabalho. O método utilizado foi a análise de conteúdo que, segundo Bardin (2010), é caracterizada por um conjunto de instrumentos metodológicos, que podem ser sutis e que se aplicam a discursos extremamente diversificados. Os discursos diversificados são aplicados devido às distintas características das empresas de marketplace entrevistadas. Foram realizadas sete entrevistas entre dezembro de 2016 a janeiro de 2017, as quais foram gravadas com o consentimento dos entrevistados, para posterior transcrição.

Portanto, a análise de conteúdo foi o método mais apropriado para este artigo, pois trabalha com a materialidade linguística, através de condições empíricas do texto, estabelecendo categorias para sua interpretação (CAREGNATO e MUTTI, 2006). O quadro 1 apresenta características das empresas analisadas como o número de usuários (produtores) e assinantes (consumidores), além dos cargos dos entrevistados. Importante destacar que as empresas M4 e M6 constam com dados do número de usuários e de anunciantes Não Informado, pois ambas empresas estavam em processo de aporte financeiro de investidores-anjo, o que os impediram de passar as informações no momento da entrevista.

\section{Quadro 1: Dados das Empresas Entrevistadas}

\begin{tabular}{|c|c|c|c|c|}
\hline Empresa & Atuação & $\mathbf{N}^{\mathbf{0}}$ de Usuários & $\mathbf{N}^{\mathbf{0}}$ de Anunciantes & Cargo do Entrevistado \\
\hline$M 1$ & América Latina & 121 milhões & 155.000 & Gerente \\
\hline$M 2$ & $\begin{array}{c}\text { Brasil, Argentina e } \\
\text { Colômbia }\end{array}$ & 11 milhões & 73.000 & Sócio Fundador \\
\hline$M 3$ & Brasil & 53.000 & 23 & Gerente Geral \\
\hline$M 4$ & Brasil & Não Informado & Não Informado & Sócio Fundador \\
\hline$M 5$ & Brasil & 25.000 & 500 & Gerente de Marketing \\
\hline$M 6$ & São Paulo & Não Informado & Não Informado & Sócia Fundadora \\
\hline$M 7$ & Brasil & 55.520 & 890 & Sócio Fundador \\
\hline
\end{tabular}

Fonte: Elaborada pelos autores.

Com o quadro 1 é possível observar a grande diferença entre os marketplaces entrevistados, tanto no tamanho da empresa e atuação, o que possibilitou uma análise diversificada deste setor no Brasil. Como o foco deste estudo foi entender como ocorre a criação de vantagem competitiva no segmento marketplace, as empresas selecionadas foram as que atuam somente no marketplace e não outras, denominadas de híbridas, como Extra.com, Netshoes.com, Magazineluiza.com, entre outros.

Para a interpretação das informações foram utilizadas as respostas fornecidas pelos entrevistados, as quais foram identificadas com base nas Unidades de Registro, que, segundo 
Bardin (2010) consistem nas palavras ou expressões relacionadas ao tema central de cada pergunta aberta feita ao entrevistado. Como ferramenta tecnológica foi utilizado o software Qualitative Solutions Research NVivo (QSR NVivo) 11.0 para a análise documental, que segundo Bardin (2010), é o processo pelo qual os dados brutos são reunidos um documento secundário, representando essa informação de outro modo.

O QSR NVivo 11.0 tem como função primordial a codificação de texto e armazenamento em conjuntos específicos, os quais são: documentos (para armazenagem das entrevistas); nós (para codificação e categorização) e atributos (constam as características dos sujeitos - cargo, empresa, entre outros). O programa também permite identificar a frequência (unidades de registro) e categorização presentes em cada categoria. Assim, a Tabela 1 - Frequência de palavras e expressões mais citadas nas entrevistas demonstra as unidades de registro encontradas.

Tabela 1: Frequência de palavras e expressões mais citadas nas entrevistas.

\begin{tabular}{|l|c|c|c|c|c|c|c|c|}
\cline { 2 - 9 } \multicolumn{1}{c|}{} & $M 1$ & $M 2$ & $M 3$ & $M 4$ & $M 5$ & $M 6$ & $M 7$ & TOTAL \\
\hline Serviço & 14 & 22 & 12 & 12 & 6 & 10 & 9 & 85 \\
\hline Cliente & 15 & 9 & 33 & 9 & 6 & 2 & 2 & $\mathbf{7 6}$ \\
\hline Tecnologia & 30 & 7 & 1 & 7 & 0 & 0 & 3 & $\mathbf{4 8}$ \\
\hline Diferenciação & 4 & 6 & 13 & 10 & 3 & 7 & 3 & $\mathbf{4 6}$ \\
\hline Inovação & 9 & 12 & 6 & 9 & 0 & 1 & 4 & 41 \\
\hline E-Commerce & 9 & 6 & 3 & 8 & 2 & 2 & 1 & $\mathbf{3 1}$ \\
\hline Mudança & 5 & 6 & 1 & 2 & 2 & 1 & 0 & $\mathbf{1 7}$ \\
\hline Cultura & 8 & 2 & 0 & 0 & 1 & 0 & 1 & $\mathbf{1 2}$ \\
\hline
\end{tabular}

Fonte: Elaborada pelos autores.

Após a frequência ser mensurada, foi feito o agrupamento das Unidades de Registro em Unidades de Significado, que Bardin (2010) considera-as como uma unidade de informação em que exista uma ligação com os pontos abordados na teoria e que contribua para um entendimento do estudo. Pogré e Lombardi (2006) também confirmam a importância de construir uma matriz de tipificação em pesquisas qualitativas, pois essa é uma ferramenta que auxilia a pesquisa, tornando-a mais rápida e eficiente a análise. Com isto, a utilização do software QSR NVivo 11.0 contribuiu para a análise de conteúdo, em razão que ela constitui em um método de tratamento de comunicações bastante amplo, conforme os objetivos metodológicos da pesquisa, emergindo a necessidade do emprego de técnicas computacionais (MOZZATO e GRZYBOVSKI, 2011).

As unidades de significado aferidas foram a relação dos termos Serviços, Tecnologia e Diferenciação, os quais tiveram grande destaque e na maioria dos momentos estavam conectados, demonstrando que as empresas trabalham a tecnologia em seus serviços com o objetivo de se diferenciar no mercado, o que está alinhado com os estudos de Ansoff (1965), Porter (1989) e Faoro et al (2014), os quais escrevem que a diferenciação é um dos tipos básicos 
de vantagem competitiva que as organizações podem possuir e que a tecnologia é um formato utilizado na busca pela diferenciação.

O termo Inovação integrado com Mudança e Cultura também teve destaque, apontando como mais uma unidade de significado encontrada na pesquisa, mas é importante destacar que "cultura" pode ser abordada de diferentes maneiras, mas para este artigo, utilizamos a visão em nível organizacional, onde o indivíduo segue um comportamento de acordo com seu local de trabalho (MACHADO, 2004). Em complemento, Macedo (2012) escreve que a cultura organizacional influencia os valores da empresa e, neste sentido, uma empresa inovadora necessita ter um clima que estimule a inovação. As categorias encontradas que são relevantes para este artigo foram: "diferenciação como fonte de vantagem competitiva" e "cultura de inovação para a geração de vantagem competitiva". Para melhor analisar os resultados encontrados, estes dois nós foram divididos em subtópicos:

\subsection{Diferenciação como fonte de vantagem competitiva}

O primeiro achado relevante para este artigo foi que a diferenciação é fonte de vantagem competitiva para as empresas entrevistadas. Esta diferenciação surge por meio dos diferentes tipos de inovação, como nos casos da empresa M1, que mudou a forma de calcular o frete e acompanhar as entregas, a empresa M2 e a M3 que alteraram o modo de comunicação com seus parceiros e clientes, se enquadram na inovação em processos. Estas diferenciações são uma defesa contra a rivalidade competitiva, atuando através da facilidade gerada aos clientes e da consequente fidelização em relação à marca, tendo como resultado uma menor sensibilidade destes clientes quanto aos preços, por exemplo (PORTER, 1989; FAORO et al, 2014). Em outros casos, a diferenciação foi gerada por uma inovação de paradigma como no caso da empresa M4, que desenvolveu um novo canal de venda com embaixadores das marcas parceiras e da M7, que inovou quando desenvolveu sua plataforma focada em consultoria de voluntariado para empresas. Por fim, as empresas M5 e M6 que buscaram sua diferenciação por meio de uma inovação de marketing, criando nova maneiras de vender roupas e comida, respectivamente. Estes tipos de inovação são descritos por Tidd e Bessant (2015) como sendo potenciais para a busca de diferenciação, a qual é importante para a criação de uma vantagem competitiva (BARNEY e HESTERLY, 2008). Segundo Porter (1989), a diferenciação tecnológica é fator de geração de vantagem competitiva, tendo em vista que a tecnologia envolvida no processo está contida na cadeia de valores de uma firma.

Isto pode ser comprovado por números que mostram o aumento do faturamento nas empresas após a inovação, como é o caso da M1 que apresentou um crescimento de $60 \%$ no faturamento no Brasil, após sua inovação em processos, segundo o entrevistado. Isto também ocorreu com a empresa M7, o qual sua inovação de paradigma (consultoria de voluntariado para empresas) fez o faturamento atual da empresa advir $90 \%$ deste novo serviço. Já para a empresa M2, as inovações incrementais contribuíram para o crescimento de $80 \%$ entre os anos de 2014 e 2015 e que sua mais recente inovação, ainda está sendo implementada, por isto não tem números mais exatos. Com isto, é importante ver que as inovações contribuíram para a criação da vantagem competitiva, pois o aumento do faturamento proporciona uma posição superior das empresas perante seus concorrentes (ANSOFF, 1965; PORTER, 1989). 


\subsection{Cultura de inovação para a geração de vantagem competitiva}

Outro achado interessante da pesquisa foi referente ao modo que os marketplaces trabalham a inovação. Somente uma empresa possui um departamento de inovação em sua estrutura organizacional. Nas outras, muito pela estrutura enxuta, a inovação faz parte da cultura, do DNA. Tanto que estes termos ("inovação faz parte da cultura da empresa" e "inovação está no DNA da nossa empresa") apareceram em 5 das 7 entrevistas. Estas empresas fazem reuniões multisetoriais (agregando áreas de produtos, marketing, vendas, tecnologia, logística) sazonalmente para discutir os processos e novas estratégias de mercado. Isto faz com que cada uma destas áreas tenha projetos ligados à inovação em andamento e nestas reuniões são definidos os projetos que irão fazer parte do escopo de estratégias de inovação. Quatro empresas citaram exemplos de novos produtos ou processos que foram criados por este método.

A relação entre inovação e cultura é natural como o próprio desenvolvimento da cultura organizacional, pois os trabalhadores necessitam conviver com a inovação para incorpora-la em seu cotidiano (MACHADO, 2004). Isto está presente na fala do CEO da empresa M2, que citou "Aqui, o processo de inovação é muito participativo. Quando estamos pensando em algo novo, as pessoas são envolvidas desde o brainstorm para o desenvolvimento de um novo produto ou processo".

A inovação é tratada como algo fundamental nas competências essenciais dos funcionários das empresas entrevistadas, como é explicitada por um entrevistado da empresa M1 - "Inovação são as pessoas que a gente contrata, o perfil delas. Em todas as áreas a gente precisa ter inovação. [...] a gente tem que ter inovação em todas as áreas e o tempo inteiro".

O CEO da empresa M4 comenta que todos têm que estar conectados, por isto eles comparecem em todas as grandes feiras de inovação no Vale do Silício, no MIT (Massachusetts Institute of Technology) e na Nova Zelândia, além de também fazerem reuniões mensais de avaliações de desempenho, de status dos projetos e a inovação é um dos tópicos abordados.

Um dos principais resultados analisados nesta pesquisa foi que todas as empresas trabalham a inovação como algo intrínseco de sua estrutura e eles acreditam que ela é fonte de vantagem competitiva, pois elas geram a diferenciação de sua organização perante o mercado.

Entretanto, mesmo com a inovação sendo trabalhada de maneira mais tácita, ela está envolvida em processos sistematizados para o desenvolvimento de novos processos e produtos/serviços, de uma maneira mais aberta, em consonância com que autores como Chesbrough (2012), McGrath (2014) e Carvalho et al (2015) escrevem a respeito da importância da inovação ser sistemática, constante em seu modelo de negócio, e contínua para propiciar uma vantagem competitiva e contribuir para a organização.

Este achado amplia o olhar sobre inovação tratado até aqui neste artigo, trazendo o conceito de Inovação Aberta (Open Innovation), termo criado em 2003 por Henry Chesbrough que descreve como as organizações que promovem ideias, pensamentos, processos e pesquisas abertos, tendem a serem mais eficientes, tendo em vista todo o potencial de mais agentes contribuindo no processo de inovação.

A inovação tradicional é considerada "fechada", pois é uma abordagem focada internamente, estando cada vez mais em desacordo com o conhecimento no cenário do século XXI. Neste caso, em vez de depender somente de P\&D (Pesquisa e Desenvolvimento) interno, as empresas têm buscado desenvolver a inovação aberta (BENEVIDES et al, 2016).

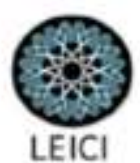


Trentini et al (2012) citam que este modelo é considerado "fechado" pois têm somente uma entrada (departamento de P\&D) e uma saída (o mercado). Para Chesbrough (2012b), o desafio que toda empresa deve encarar ao se tornar mais aberta é a resistência interna às inovações e tecnologia externas. Esta resistência interna é conhecida como a síndrome do "não foi inventado aqui". Assim, foi possível observar na presente pesquisa que, incluindo todas as áreas e empregados das organizações, a contribuição e comprometimento das pessoas no processo de inovação, fazem com que podemos afirmar que os marketplaces analisados utilizam conceitos da inovação aberta, pois consideram a capacidade da empresa em conectar e desenvolver soluções mais importante do que um departamento de Pesquisa e Desenvolvimento interno ser a única fonte de inovação para as organizações. A inovação passa a fazer parte de um fluxo que tanto pode ser do ambiente interno ao externo e vice-versa, em um processo colaborativo, se utilizando de caminhos e interações internas e externas para acelerar o processo de inovação (CHESBROUGH, 2012; PITASSI, 2012; TRENTINI et al, 2012).

\section{Conclusões}

O presente artigo teve como objetivo "identificar como ocorre a criação de vantagem competitiva setor marketplace". Com os estudos bibliográficos e a pesquisa feita, foi possível verificar que a criação de vantagem competitiva neste setor se dá pela diferenciação, a qual é oriunda da inovação. Isto corrobora com pesquisas de autores como Consoni et al (2010), Silva e Dacorso (2013) e Zilber, Perez e Lex (2009), que verificaram a relação entre estes constructos em outros segmentos.

Por meio da análise dos resultados da pesquisa também foi possível verificar que o modo que as empresas deste setor trabalham inovação está ligada à cultura, tendo uma forte tendência à inovação aberta. O que está alinhado com a pesquisa de Machado (2004), a qual cita que as organizações inovadoras são aquelas que têm inovação em seu resultado final e possuem subsídios que formam uma cultura propícia e incentivadora ao desenvolvimento das inovações.

Este artigo também pôde comprovar que a inovação pode ser fonte de vantagem de competitiva com base em autores como Ansoff (1965), Porter (1989) e Barney e Hesterly (2008) e foi atestado na pesquisa no setor de marketplace, onde as empresas utilizam a inovação - seja de processos, produtos ou de paradigma - como base para a diferenciação (TIDD e BESSANT, 2015). Além disto, também foi possível atestar a presença da tecnologia como catalisador da inovação (CHESBROUGH, 2012).

Importante ressaltar que mesmo com achados relevantes para o setor do marketplace, ainda tem muito a ser estudado sobre este recente modelo de negócio que está em crescimento no Brasil. Assim, existem oportunidades de estudos mais generalistas buscando entender melhor as tendências do marketplace e também dos outros atores envolvidos no processo, como os sellers (vendedores), que muitas vezes são microempresários.

\section{Referências Bibliográficas}

ALSTYNE, Marshall W. V.; PARKER, Geoffrey G.; CHOUDARY, Sangeet P. Pipelines, plataformas e novas regras de estratégia. Harvard Business Review, v.94, n.4, p. 32-40, Abril de 2016.

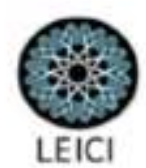


AMIT, Raphael; SCHOEMAKER, Paul JH. Strategic assets and organizational rent. Strategic management journal, v. 14, n. 1, p. 33-46, 1993.

ANSOFF, H. Igor. Corporate strategy: An analytic approach to business policy for growth and expansion. McGraw-Hill Companies, 1965.

BARDIN, Laurence. Análise de conteúdo. Lisboa: Edições 70, 2010.

BARNEY, Jay B.; HESTERLY, William S. Administração estratégica e vantagem competitiva. Pearson Prentice Hall, 2008.

BARNEY, Jay. Firm resources and sustained competitive advantage. Journal of management, v. 17, n. 1, p. 99-120, 1991.

BARROS, Aidin de J. P.; LEHFELD, Neide A. de S.. Projeto de pesquisa: propostas metodológicas. Petrópolis: Vozes, 2003.

BENEVIDES, Gustavo; OLIVEIRA, Erick C.; MENDES, Rodrigo O. B.. A utilização do modelo de inovação aberta como ferramenta competitiva um APLs. Revista Alcance, v. 23, n. 1, p. 004-018, 2016.

BOGERS, Marcel; AFUAH, Allan; BASTIAN, Bettina. Users as innovators: a review, critique, and future research directions. Journal of management, 2010.

BRUYAT, C., JULIEN, P.A. Defining the field of Research in Entrepreneurship.

CAMPOS, Rafael et al. Marketplace, a salvação da lucratividade do e-Commerce. Relatório da VTEX e BR Partners. São Paulo: 2015.

CAREGNATO, Rita Catalina Aquino; MUTTI, Regina. Pesquisa qualitativa: análise de discurso versus análise de conteúdo. Texto contexto enferm, v. 15, n. 4, p. 679-84, 2006.

CARNETI, Karen. Brasil é o país que mais cresce no Mercado Livre na América Latina, 2015.

Disponível em <http://exame.abril.com.br/tecnologia/noticias/brasil-e-o-pais-que-mais-cresceno-mercado-livre-na-america-latina-afirma-executivo-da-empresa>. Acesso em 14 de outubro de 2017.

CHESBROUGH, Henry William. Inovação aberta: como criar e lucrar com a tecnologia. Porto Alegre: Bookman, 2012.

CHESBROUGH, Henry William. Modelos de Negócios Abertos: Como prospectar no novo cenário da inovação. Porto Alegre: Bookman, 2012b.

CHRISTENSEN, Clayton M. The past and future of competitive advantage. MIT Sloan

Management Review, v. 42, n. 2, p. 105, 2001.

CONSONI, Diogo José, et al. A inovação como vantagem competitiva no setor automobilístico.

Jovens Pesquisadores-Mackenzie, v. 3, n. 1, 2010.

CRESWELL, John W. Projeto de pesquisa métodos qualitativo, quantitativo e misto. In: Projeto de pesquisa métodos qualitativo, quantitativo e misto. Artmed, 2010.

DE CARVALHO, Gustavo Dambiski Gomes, et al. Radar da inovação como ferramenta para o alcance de vantagem competitiva para micro e pequenas empresas. Revista de Administração e Inovação (RAI), v. 12, n. 4, p. 162, 2015.

DE DADOS SOBRE INOVAÇÃO 1997, 184 p; produção ARTI /FINEP, tradução de Flávia Gouveia - 3.ed, 2005. Bibliografia: p. 149-151, ISBN 92-64-01308-3.

DE OSLO, Manual. Manual de Oslo, 2005. Disponível em $<$ http://gestiona.com.br/wpcontent/uploads/2013/06/Manual-de-OSLO-2005.pdf $>$. Acesso em 05 de outubro de 2017.

DRUCKER, Peter F. Desafios gerenciais para o século XXI. São Paulo: Thomsom, 2001. 
E-BIT. Relatório Webshoppers $35^{\mathbf{a}}$ edição $\quad$ - 2017. Disponível em http://www.ebit.com.br/webshoppers. Acesso em 12 de janeiro de 2017.

FAORO, Roberta Rodrigues et al. Diferenciação e Foco para obtenção de Vantagem Competitiva: O Caso da Beta Sistemas. Revista Eletrônica de Administração, v. 20, n. 3, p. 838-856, 2014.

FORSMAN, Helena. Innovation capacity and innovation development in small enterprises. A comparison between the manufacturing and service sectors. Research Policy, v. 40, n. 5, p. 739-750, 2011.

GOMES, Clandia M. et al. Indicadores e características da gestão de fontes externas de informação tecnológica e do desempenho inovador de empresas brasileiras. Revista de Administração Contemporânea (RAC), v. 13, n. 2, p. 172-188, 2009.

GRANT, R. M. Contemporary Strategy Analysis: Concepts, Techniques, Applications. Oxford: Blackwell Publishers Ltd, v. 16, p. 17, 2008.

LEVINE, D. M.; et al. Estatística: teoria e aplicações. 5. ed. Rio de Janeiro: TLC, 2008.

MACEDO, Maria Teresa Ferreira Cordovil de et al. Inovação aberta: um estudo sobre a inovação aberta na literatura internacional e nacional. 2012.

MACHADO, Denise del Prá Netto. Inovação e cultura organizacional: um estudo dos elementos culturais que fazem parte de um ambiente inovador. 2004. Tese de Doutorado.

MATTAR, Fauze et al. Pesquisa de Marketing, $7^{\text {a }}$ Edição. Elsevier Brasil, 2014.

MCGRATH, Rita. O Fim da Vantagem Competitiva: Um Novo Modelo De Competição Para Mercados Dinâmicos. Elsevier Brasil, 2014.

MONTGOMERY, Cynthia A. et al. Estratégia: a busca da vantagem competitiva. Rio de Janeiro: Campus, p. 419-440, 1998.

MOZZATO, Anelise Rebelato; GRZYBOVSKI, Denize. Análise de conteúdo como técnica de análise de dados qualitativos no campo da administração: potencial e desafios. Revista de Administração Contemporânea, v. 15, n. 4, p. 731-747, 2011.

PENROSE, Edith T. The theory of the growth of the firm. New York: Sharpe, 1959.

PITASSI, Claudio. Inovação aberta na perspectiva das empresas brasileiras de base tecnológica: proposta de articulação conceitual. RAI Revista de Administração e Inovação, v. 9, n. 3, p. 77-102, 2012.

POGRÉ, P.; LOMBARDI, G. O ensino para a compreensão. Vila Velha: Hoper, p. 23, 2006. PORTER, Michael E.. Vantagem competitiva: criando e sustentando um desempenho superior. (E. M. P. Braga, Trad.). Rio de Janeiro: Campus, 1989.

PRAHALAD, Coimbatore K.; HAMEL, Gary. The core competence of the corporation. 1990. ROBERTSON, Thomas S. Em prol da revitalização. FINANCIAL times: dominando administração. São Paulo: Makron, p. 193-199, 1999.

RONDANI, Bruno; ANDREASSI, Tales; BERNARDES, Roberto. Microfoundations for Open Innovation: is effectuation a valid approach for open innovation managers? Revista

Gestão \& Conexões, v. 2, n. 1, p. 94-115, 2013.

ROPER, S.; ARVANITIZ, S. From knowledge to added value: A comparative, panel-data analysis of the innovation value chain in Irish and Swiss manufacturing firms. Research Policy, 2012.

SCHUMPETER, J. A. Business cycles, v. I. New York: McGraw Hill Books, 1939. 
SHANE, S. A. General theory of entrepreneurship: new horizons in entrepreneurship. North Hampton: Edward Elgar, 2003.

SILVA, Glessia; DACORSO, Antonio L. R.. Inovação aberta como uma vantagem competitiva para a micro e pequena empresa. DOI: 10.5773/rai. v10i3. 1036. RAI: revista de administração e inovação, v. 10, n. 3, p. 251-268, 2013.

SOARES, Leandro. O E-marketplace e sua importância para o comércio atual, 2013. Disponível em <https://ecommercenews.com.br/artigos/cases/o-e-marketplace-e-sua-importancia-para-ocomercio-atual>. Acesso em 06 de outubro de 2017.

SZETO, Elson. Innovation capacity: working towards a mechanism for improving innovation within an inter-organizational network. The TQM Magazine, v. 12, n. 2, p. 149-158, 2000.

TIDD, J. et al. Managing innovation: integration technological, market and organizational change. $3^{\text {rd }}$. Ed. John Willey \& Sons, Ltd., 2005.

TIDD, Joe; BESSANT, John. Gestão da Inovação - 5.ed. Porto Alegre: Bookman Editora, 2015.

TIRONI, Luís F.; CRUZ, Bruno de O. Inovação incremental ou radical: há motivos para diferenciar? Uma abordagem com dados da PINTEC. 2008.

TRENTINI, Anny Margaly Maciel, et al. Inovação aberta e inovação distribuída, modelos diferentes de inovação? Revista Eletrônica de Estratégia \& Negócios, v. 5, n. 1, p. 88-109, 2012.

VIANNA, Maurício, et al. Como as empresas brasileiras inovam na prática. Harvard Business Review, v.94, n.4, p. 51-57, Abril de 2016.

WE ARE SOCIAL. Digital, Social \& Mobile Worldwide in 2015. Disponível em $\langle$ http://wearesocial.com/uk/special-reports/digital-social-mobile-worldwide-2015>. Acesso em 10 de outubro de 2017.

WIGAND, R. T. (1997). Electronic commerce: Definition, theory, and context. The WINTER, S. Knowledge and competence as strategic assets. The strategic management of intellectual capital, v. 187, 1998.

ZILBER, Moises Ari, et al. A inovação e os fatores organizacionais característicos. Revista de Ciências da Administração, v. 10, n. 21, p. 76, 2008.

ZILBER, Moisés Ari; PEREZ, Gilberto; LEX, Sérgio. Inovação tecnológica e obtenção de vantagens competitivas: um estudo duplo qualitativo na indústria brasileira de equipamentos eletro-médicos. Organizações \& Sociedade, v. 16, n. 51, 2009. 